\section{Formação Paideia para o Apoio Matricial: uma estratégia pedagógica centrada na reflexão sobre a prática}

\author{
Paideia training for matrix support: a pedagogical \\ strategy centered on reflection of practice
}

\author{
Formación según Paideia para el apoyo matricial: \\ una estrategia pedagógica centrada en la \\ reflexión sobre la práctica
}

Mônica Martins de Oliveira Viana 1

Gastão Wagner de Sousa Campos 1

doi: 10.1590/0102-311X00123617

\section{Resumo}

A pesquisa analisou a utilização do Método Paideia na formação de profissionais que utilizam Apoio Matricial em Curitiba (Paraná), Uberlândia (Minas Gerais) e Campinas (São Paulo), Brasil. Para isso, foi desenvolvido um processo de formação (Curso de Especialização), segundo a estratégia Paideia, com 18 meses de duração, para profissionais do Apoio Matricial. Trata-se de pesquisa qualitativa, que se inspira na pesquisa-ação, na pesquisa-intervenção e na avaliação por triangulação de métodos. $\mathrm{Na}$ produção dos dados, foram utilizados as estratégias de observação em campo com registro em diário de campo, a entrevista semiestruturada por meio de questionário e o grupo focal. Para os dados obtidos com os questionários, foi feita uma análise descritiva. Já os dados qualitativos obtidos por meio da observação participante e dos grupos focais foram analisados por meio da construção de narrativas. O estudo apontou que a Formação Paideia favoreceu mudanças no processo de trabalho e na prática clínica das equipes investigadas. Observou-se, contudo, que a plena utilização da metodologia de Apoio Matricial é fortemente influenciada pelo contexto institucional, pelos modelos de gestão e de atenção, sendo constatada diferença importante entre os campos conforme o grau de democratização e de apoio da gestão a mudanças organizacionais.

Práticas de Saúde Pública; Desenvolvimento de Pessoal; Capacitação de Recursos Humanos em Saúde; Gestão em Saúde
Correspondência

M. M. Oliveira Viana

Rua dos Guatás 250, apto. 41B, Campinas, SP 13081-060, Brasil.

monica.psisaude@gmail.com

1 Universidade Estadual de Campinas, Campinas, Brasil. 


\section{Introdução}

Na atual configuração do Sistema Único de Saúde (SUS), a atenção à saúde está organizada de modo descentralizado e hierarquizado, a partir da articulação entre os níveis primário, secundário e terciário, tendo, na atenção primária, seu ponto estratégico de acesso e de ordenação do cuidado em rede. Espera-se que a atenção primária constitua a entrada preferencial dos usuários no SUS e que seu processo de trabalho esteja pautado nos princípios da universalidade, integralidade, equidade e controle social. Recomenda-se ainda a vinculação entre equipes e usuários com base em território e famílias, de modo a possibilitar a realização de ações individuais e coletivas voltadas para a promoção e a proteção da saúde, a prevenção de agravos, o diagnóstico, o tratamento, a reabilitação, a redução de danos e a manutenção da saúde 1 .

Para Starfield 2,3 a atenção primária detém elevado potencial de resolubilidade, podendo resolver cerca de $80 \%$ dos casos atendidos. E, se contar com a participação de especialistas no arranjo de cuidado compartilhado, esse potencial apresenta maiores chances de se efetivar.

A metodologia de Apoio Matricial inspirou o projeto e a implementação dos Núcleos de Apoio à Saúde da Família (NASF), arranjo organizacional que permite a inserção de especialistas (assistentes sociais, fonoaudiólogos, pediatras, psiquiatras, geriatras, psicólogos, fisioterapeutas, terapeutas ocupacionais, entre outros) na atenção primária brasileira. Os NASF devem oferecer suporte técnico-assistencial e pedagógico às equipes de saúde da família ou de atenção básica 1,4,5, podendo efetivar-se como arranjo de cuidado compartilhado e elevar a resolutividade da atenção primária.

Com a regulamentação das Portarias no 2.488, de 21 de outubro de 2011 6, e no 3.124, de 28 de dezembro de 2012 7, houve uma ampliação da atuação das equipes de NASF, abrindo-se a possibilidade de que qualquer município do Brasil faça implantação de equipes NASF, desde que tenha, ao menos, uma equipe de saúde da família e prevê, ainda, a criação de equipes NASF para apoiar equipes de atenção básica que cuidam de populações específicas (consultórios na rua, equipes ribeirinhas e fluviais) e do Programa Academia da Saúde.

Aos especialistas que compõem os NASF ou equipes de Apoio Matricial, cabem a promoção do trabalho interdisciplinar e a ativação dos espaços de comunicação para o compartilhamento de saberes e para a organização dos fluxos na rede de atenção à saúde e nas ações de território, rompendo com a burocratização presente no sistema de referência/contrarreferência e desfazendo a lógica de encaminhamentos impessoais e de fragmentação do cuidado 8,9,10.

Para Tesser 11, é fundamental que as equipes de Apoio Matricial e de NASF não sejam subutilizadas em sua relação com a atenção primária. Assim, Tesser 11 e Tesser \& Poli Neto 12 sugerem que tais equipes sejam capazes de conciliar as atividades compartilhadas e de território com o cuidado individual especializado referente ao núcleo de saber dos profissionais, oferecendo um modelo alternativo de atenção secundária, reconhecida como deficiente no SUS.

Entretanto, é preciso evitar o risco de incorrer em práticas ambulatoriais tradicionais, pautadas pela fragmentação do trabalho e pelo "produtivismo", pois foram apontados como fatores de precarização do cuidado e de frustração entre os profissionais 9,13.

Ademais, como os NASFs e o uso de Apoio Matricial foram inseridos no SUS há pouco tempo, é preciso aprofundar as investigações, os desafios que se impõem ao seu desenvolvimento e buscar respostas que preservem a potencialidade do trabalho interdisciplinar entre as equipes 8 .

Para Feuerwerker 14, Oliveira 15 e Melo 16, uma das estratégias a serem utilizadas para aprimorar o trabalho dos profissionais do Apoio Matricial, rever o processo de atuação e promover novos processos de subjetivação e de gestão do cuidado seria a implementação de dispositivos de formação e de educação permanente que priorizassem a reflexão sobre a prática. O objetivo dessa estratégia pedagógica formação com base na reflexão sobre a prática concreta dos profissionais - busca romper aspectos cristalizados nas instituições de saúde e poderia contribuir para a formação ampliada dos trabalhadores.

Para Oliveira 13 e Oliveira ${ }^{15}$, a função de apoiador sugere a incorporação de referenciais, habilidades e ferramentas do Apoio Paideia voltados para a construção de espaços democráticos de análise e deliberação dentro da perspectiva da cogestão e da habilidade de combinar conhecimentos dos respectivos núcleos de saber com aqueles referentes ao campo da Atenção Primária e da Saúde Coletiva, tais como o manejo de grupo, desenvolvimento de projetos terapêuticos singulares e ações no território. 
O papel estratégico das equipes de Apoio Matricial ou das equipes NASF na atenção primária, a complexidade do trabalho a ser realizado, a multiplicidade de conhecimentos e habilidades requeridas, combinados à recente difusão dessa metodologia e da quase ausência de debates e de capacitação em apoio nos cursos de graduação 13,14,15 reafirmam a necessidade de investimentos na formação e educação permanente desses profissionais.

Contudo, é imprescindível que o modelo tradicional de ensino nas áreas da saúde, reconhecido por seu formato centrado em conteúdos e disciplinas fragmentadas, seja superado 17,18,19,20.

A lógica do trabalho em cogestão, como proposto no Apoio Matricial, demanda uma formação que se aproxima daquela defendida por Oury ${ }^{21}$, que prioriza processos e ferramentas conceituais que permitam extrair do campo do cotidiano o material da aprendizagem.

Modelos como os da educação permanente 22, da aprendizagem baseada no trabalho, descrita por Raelin 23 e Billett 24, e da aprendizagem baseada em problemas (problem-based learning), avaliada na metanálise efetuada por Vernon \& Blake 25, têm sido utilizados como fontes de inspiração para processos de formação pautados na reflexão sobre a prática.

Todavia, tendo em vista a dificuldade em se instituir, no SUS essas estratégias de formação e a baixa efetividade de capacitações acerca do trabalho compartilhado, conforme apontado por Gonçalves et al. 26, permanece a relevância de realização de novas experiências e de pesquisas.

Dentro do campo de formação com base na prática, o Apoio Paideia tem sido utilizado como uma proposta pedagógica para a formação de profissionais da saúde nas temáticas da clínica ampliada e de gestão compartilhada 27,28,29,30,31,32.

Trata-se de empregar o próprio Método Paideia, em sua dimensão pedagógica, para a formação de trabalhadores. Constituindo, assim, o que se poderia chamar de uma Formação Paideia.

Essa formação, reunindo elementos do construtivismo, do materialismo dialético sócio-histórico, da pedagogia do oprimido, da psicanálise e outros, busca articular teoria e prática. Trabalha com referência aos eixos do saber, afeto e poder. Promove um método interativo entre professor e estudante, estimulando posturas ativas bilaterais por meio de ofertas teóricas, discussão de casos e projetos de intervenção, incentivando, além da incorporação de novos conceitos e paradigmas, a realização de intervenções concretas, ligadas às relações de poder, à gestão e à política, integradas à clínica 32.

A presente pesquisa buscou analisar a utilização desse modelo da Formação Paideia para os profissionais do Apoio Matricial, elencando algumas de suas potencialidades e limitações. Assim, a partir da avaliação de processo de capacitações realizadas em três municípios de grande porte, reuniram-se subsídios para a compreensão dessas novas estratégias pedagógicas, buscando-se, ainda, ampliar o repertório a ser utilizado para a qualificação dos recursos humanos do SUS, como recomendado pela Lei Orgânica no 8.080/1990 33.

\section{Metodologia}

A pesquisa, aprovada pelo Comitê de Ética da Faculdade de Ciências Médicas da Universidade Estadual de Campinas (UNICAMP), parecer 972.660/15 (CAAE 41375215.1.0000.5404), apresenta desenho qualitativo, inspirado na combinação de elementos metodológicos oriundos da pesquisa-ação educacional 34,35, da pesquisa-intervenção 35,36,37 e da avaliação por triangulação de métodos 38, tendo como objeto a Formação Paideia, realizada em Campinas (São Paulo), Curitiba (Paraná) e Uberlândia (Minas Gerais), durante o período de 2015 e 2016.

A Formação Paideia, nosso objeto de estudo, consistiu em um Curso de Especialização em Apoio Matricial em Saúde, com 18 meses de duração e uma carga horária de 373 horas (256 presenciais e 117 a distância). Contou com 121 inscritos e com uma taxa de desistência de 16,53\% ao longo do curso, estando abaixo daquela encontrada por Gonçalves et al. 26 em capacitação com objetivo semelhante.

Todos os inscritos foram selecionados e indicados pelas respectivas Secretarias Municipais de Saúde, obedecendo ao critério de ser um profissional que realizasse Apoio Matricial e que obtivesse liberação do serviço para o cumprimento da carga horária do curso. E, embora todos os inscritos tenham sido convidados a participar da pesquisa, foram avisados de que sua recusa não implicaria em prejuízos à formação. Ao todo, concordaram em participar da pesquisa 85 profissionais, cuja distribuição e breve caracterização podem ser observadas na Tabela 1. 
Tabela 1

Distribuição e caracterização dos participantes que concordaram em participar da pesquisa. Cursos Campinas, São Paulo; Curitiba, Paraná; e Uberlândia, Minas Gerais, Brasil, 2016.

\begin{tabular}{|c|c|c|c|}
\hline & Campinas & Curitiba & Uberlândia \\
\hline Total inscritos [n] & 74 & 25 & 22 \\
\hline Total concluintes [n (\%)] & $64(86,5)$ & $17(68)$ & $20(90,9)$ \\
\hline Total pesquisa [n (\%)] & $52(70,3)$ & $16(64)$ & $17(77)$ \\
\hline Masculino [\%] & 6 & 19 & 11 \\
\hline Feminino [\%] & 94 & 81 & 89 \\
\hline Idade média [anos] & 38 & 35 & 36 \\
\hline \multicolumn{4}{|l|}{ Serviço de origem [\%] } \\
\hline NASF & 3 & 56 & 16 \\
\hline Atenção primária & 28 & - & 33 \\
\hline Atenção secundária (inclui CAPS) & 44 & 31 & 17 \\
\hline Atenção terciária & 12 & - & - \\
\hline Gestão & 5 & 13 & 16 \\
\hline Outros & 8 & - & 17 \\
\hline
\end{tabular}

CAPS: Centros de Atenção Psicossocial; NASF: Núcleos de Apoio à Saúde da Família.

Os inscritos foram subdivididos em grupos de vinte profissionais, reunidos por proximidade territorial dos serviços onde atuavam no período da inscrição. Cada grupo contou com a facilitação/ mediação de uma dupla de professores/apoiadores, sendo eles: um representante da Universidade e um profissional da respectiva Secretaria Municipal de Saúde, selecionados a partir do critério de possuir experiência nas temáticas do Apoio e da Metodologia Ativa de Ensino. E, para garantir que fosse utilizada a metodologia do Apoio Paideia na formação em todos os grupos, foram realizados encontros de planejamento e de acompanhamento das ações.

Segundo Tripp 34 e Pezzato \& Prado 35, denomina-se pesquisa-ação todo processo pelo qual se aprimora a prática a partir da investigação do agir, dentro da proposta de espirais reflexivas, caracterizadas por ciclos sucessivos de: (i) planejamento; (ii) ação; (iii) monitoramento dos efeitos da ação, e (iv) avaliação dos resultados. É importante lembrar que, ao fechar um ciclo de etapas, um novo se inicia, na medida em que os dados da avaliação geram subsídios para o planejamento de novas ações. Sua marca diferencial, de acordo com Molina \& Garrido ${ }^{39}$, reside em sua natureza reflexiva e autoformadora. O professor pesquisador, ao intervir, muda a realidade que estuda e, ao mesmo tempo, modifica-se a si próprio.

A pesquisa-intervenção, por seu turno, insere-se, de modo mais radical, na ruptura da dicotomia sujeito-objeto, na crítica ao positivismo e na afirmação da dimensão política das investigações. Toda a sua formulação e desenvolvimento derivam dos referenciais da Análise Institucional. Por isso, emprega a análise de implicação e da encomenda, trabalha com a produção de diários de campo e visa promover a elucidação da transversalidade e de analisadores 35,36,40.

Como nosso estudo tomou como objeto uma iniciativa pedagógica realizada simultaneamente em três municípios, com o objetivo de aprimorar estratégias de formação para o Apoio Matricial, seu caráter prático e reflexivo o aproxima de alguns dos pressupostos da pesquisa-ação educacional. Igualmente, como aconteceu a convite dos municípios e buscou empreender intervenções transformadoras das práticas institucionalizadas, também contém traços que se referem à pesquisa-intervenção.

E, por empreender avaliação do processo utilizando diferentes técnicas, de modo a possibilitar que os envolvidos se apropriassem de aspectos quantitativos e qualitativos do fenômeno, apresenta características pertinentes à triangulação de métodos, descrita por Minayo 38.

Assim, considerando o referencial metodológico, as técnicas empregadas para a produção de dados foram: (i) observação e análise do diário de campo dos professores das diferentes turmas nos três municípios (característica das pesquisa-ação e pesquisa-intervenção); (ii) questionário semiestruturado, 
aplicado no início, no meio e no fim do curso aos 85 alunos voluntários; para análise desses dados, usou-se estatística descritiva e (iii) grupo focal realizado com os voluntários no início e ao término do curso, tendo sempre entre dez e vinte participantes, bem como grupo focal efetuado ao fim da formação, com os dez professores das diferentes turmas.

Para os grupos focais, foram seguidas as diretrizes apontadas por Trad 41, Westphal et al. 42 e Minayo 38. Os roteiros foram elaborados respeitando os objetivos propostos e as diversas etapas do estudo. O grupo focal inicial priorizava as percepções dos alunos sobre práticas de apoio, relacionamento com equipes, relações de poder e expectativas sobre o curso. O grupo focal final previa a retomada das expectativas apresentadas, as mudanças nas práticas e nas relações e o papel do curso na aprendizagem sobre o Apoio Matricial. No grupo focal com os professores, o roteiro propunha como temas de discussão as práticas pedagógicas, a avaliação da proposta metodológica da Formação Paideia e os resultados percebidos.

Por fim, para o movimento de análise qualitativa e triangulação dos dados, lançamos mão de um "olhar narrativizante" a fim de estabelecer articulações entre diversos fragmentos em circulação. Esse olhar faz emergir as formas de composição do cotidiano. Aproxima-se da proposta de Ricoeur (1997, apud Furtado \& Onocko Campos 43) sobre narrativas como histórias não (ainda) narradas e simbolicamente mediatizadas.

\section{Resultados/Discussão}

\section{Proposta da Formação Paideia}

A Formação Paideia vem se delineando enquanto alternativa metodológica para a capacitação de profissionais a partir da experimentação e do empirismo intuitivo associado a considerações teóricas e a iniciativas avaliativas, conforme fica explicitado por Castro 27, Castro \& Campos 28, Cunha 29, Cunha \& Dantas ${ }^{30}$, Figueiredo 31 e Campos et al. 32 que também realizaram cursos análogos aos desenvolvidos no presente estudo.

Organizaprocesso pedagógico que busca articular teoria e prática, favorecendoa problematização 25 , a aprendizagem a partir da prática 23,24 e a transformação da realidade 13,14,16. Pretende contribuir para a ampliação da capacidade de análise e de intervenção dos coletivos, com vistas à produção de práxis voltada para o trabalho interdisciplinar e em cogestão para o cuidado integral e para a efetivação de uma clínica ampliada e compartilhada 16,32.

O curso foi iniciado a partir de um convite - uma encomenda - de grupos de trabalhadores ou de representantes institucionais da Secretaria Municipal de Saúde. A encomenda precisa ser trabalhada de modo a revelar a demanda que lhe está subjacente 44 . E, uma vez que ela não estava em desacordo com os pressupostos da Formação Paideia e com os princípios do SUS, o planejamento pôde ser iniciado.

A formação utilizou trabalho com pequenos grupos em espaços protegidos, que funcionaram como espaços transicionais, inspirados no dispositivo terapêutico descrito por Winnicott 32.

A denominação dos grupos enquanto espaços protegidos, apesar da origem na teoria dos espaços transicionais, restringiu-se, nessa pesquisa, ao contrato com os participantes de compor um setting grupal pautado pela continência e pelo estímulo ao crescimento e que, no caso da formação, incluía respeito mútuo, crítica construtiva, circulação da palavra, explicitação de conflitos e compromisso ético de não utilizar as informações ali discutidas para prejudicar colegas ou usuários. Tal compromisso mostrou-se imprescindível ${ }^{30}$ para garantir que os comentários dos participantes não se tornassem argumentos pra qualquer tipo de ameaça ou constrangimentos institucionais.

Cada grupo (turma) contou com a participação de duplas de professores/apoiadores que desempenham o papel de mediar e facilitar a construção do conhecimento, referenciado em conceitos de Vygotsky 45 e de Paulo Freire 46. Esses professores/apoiadores tinham função de facilitação e de tutoria do processo ensino-aprendizagem, considerando a demanda do grupo e elaborando ofertas oriundas da problematização de temas emergentes durante as discussões 31,32 .

O curso organizou-se em duas estratégias pedagógicas: a discussão de casos (Grupos Balint-Paideia) com elaboração de projetos de intervenção, e a de ofertas teóricas, conforme a Tabela 2. 
Tabela 2

Caracterização dos encontros presenciais realizados na Formação Paideia.

\section{Formato padrão do encontro presencial}

1. Discussão de casos e elaboração do projeto (feitos coletivamente, em roda, de modo participativo)

2. Oferta teórica (com recursos audiovisuais, discussão de texto e dinâmicas de grupo)

3. Avaliação do Encontro (alunos e professores/apoiadores avaliam o encontro)

Duração do encontro padrão

Total de encontros por turma durante a formação
Total de horas

2

$1: 30$ minutos

30 minutos

4

36

Era comum haver algum tipo de intervalo durante cada encontro. Além disso, a depender da demanda do município, era possível condensar dois encontros em um único dia, e cada turma possuía autonomia para ajustar a duração das estratégias a suas necessidades.

A discussão de casos foi sistematizada em consonância com as diretrizes apresentadas por Cunha \& Dantas 30 e Cunha 29 sobre os grupos Balint-Paideia. Derivam da metodologia dos Grupos Balint em que profissionais debatiam aspectos relacionais e emocionais da interação médico-paciente. No entanto, apresenta variações ao abordar também as questões políticas e institucionais, bem como a organização do trabalho e aspectos do modelo de atenção e de gestão. Dessa forma, os alunos eram convidados a eleger uma situação (um caso) que podia ser de um usuário, de uma família, de um território ou de uma equipe e trazê-la para que fosse colocada em análise pelo grupo e contribuísse para a reflexão sobre o papel do Apoiador Matricial. Pode-se dizer que esse recurso também favoreceria a explicitação de conhecimentos tácitos, oriundos da prática, tal como indicado por Raelin 23.

A partir do caso, os profissionais em formação foram estimulados a se comprometerem com a realização de ações junto às equipes com que trabalham. Guarda alguma semelhança com a aprendizagem grupal pautada em tarefas de Pichon-Rivière 47 mas objetivava suscitar a institucionalização de novas práticas e a reformulação do papel do Apoio Matricial.

Os aspectos fundamentais utilizados na Formação Paideia estão apresentados no esquema ilustrativo da Figura 1.

\section{Avaliação dos principais elementos da Formação Paideia: percepção dos participantes}

Nos três municípios, a avaliação foi organizada a partir de dois movimentos: o primeiro destinado a cada um dos principais elementos constitutivos da Formação Paideia, com questionários no meio e ao fim do curso, e o segundo contendo a percepção dos alunos sobre as contribuições teórico-práticas, combinando a utilização de questionários aplicados no fim do curso com os grupos focais.

Em todos os instrumentos, utilizamos escalas de 0 (zero) a 5 (cinco), nas quais, zero representava pior avaliação, e cinco, a melhor avaliação do item. Na análise descritiva, compreendemos que, frente à tendência apresentada, qualquer variação, ainda que pequena, apontava alguma mudança. Mesmo não sendo estatisticamente significativa, era qualitativamente relevante. Na Tabela 3 apresentamos a síntese das médias dos três municípios.

No comparativo entre as médias, observamos que Campinas apresentou o pior desempenho em praticamente todos os componentes, já que suas médias são ligeiramente inferiores às dos demais municípios, que, por sua vez, obtiveram índices bastante semelhantes entre si. Esse comportamento se manteve tanto na avaliação intermediária como na final.

Chamam atenção as médias inferiores atribuídas pelos participantes de Campinas, pois era esperado que o histórico de pioneirismo no município na utilização do Apoio Matricial poderia favorecer maior entusiasmo em relação a iniciativas ligadas a essa metodologia. É possível, no entanto, que as notas tenham sido influenciadas pelo pessimismo dos profissionais quanto ao futuro do Apoio, na medida em que encontramos um contexto de desmonte recente desses dispositivos 13 .

"Para alguns de nós, o curso não fez muito sentido, pois veio falar de Campinas como se ainda fosse referência e ficou meio perdido porque, na verdade, não fazemos matriciamento (...) o curso veio muito tarde, porque muito já tinha se perdido" (grupo focal de Campinas). 


\section{Figura 1}

Esquema representativo da Formação Paideia.

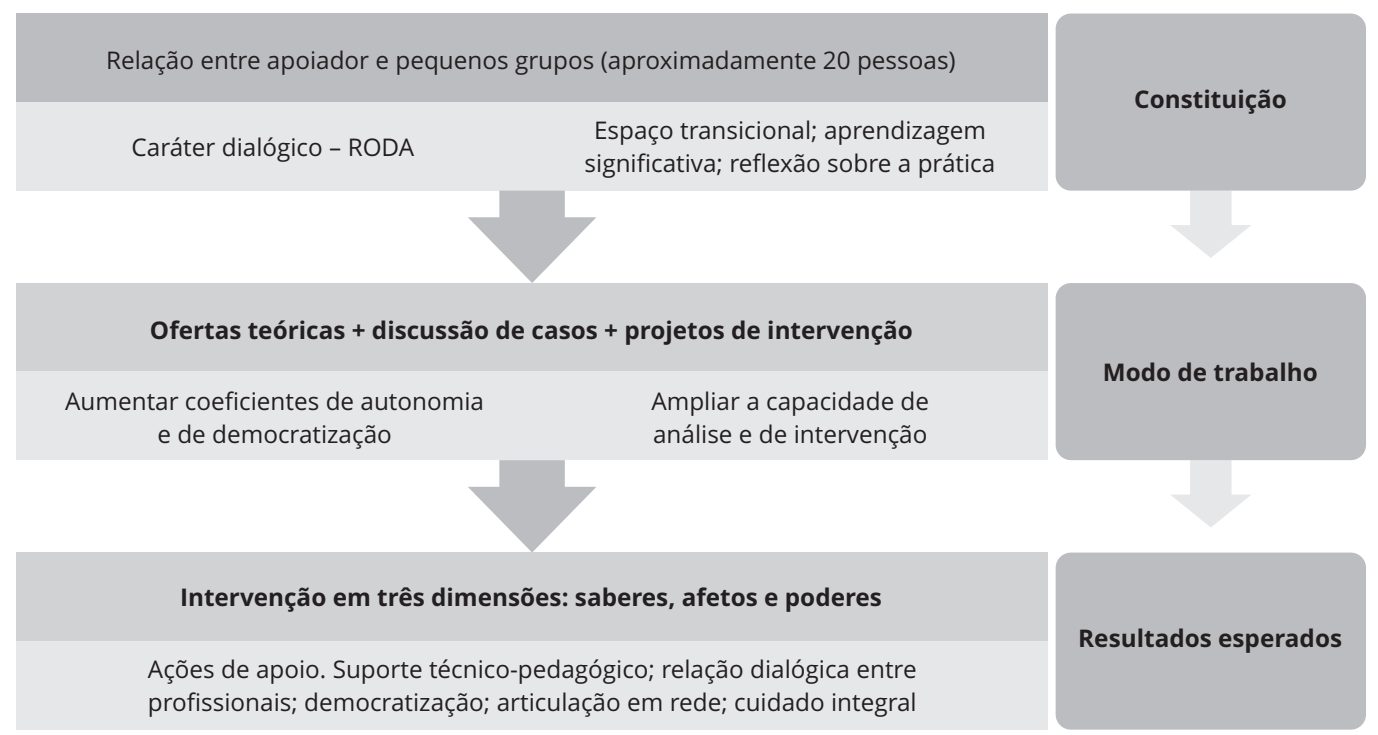

Tabela 3

Média e desvio padrão (DP) da avaliação dos componentes metodológicos da Formação Paideia.

\begin{tabular}{|c|c|c|c|c|c|c|}
\hline & \multicolumn{2}{|c|}{ Campinas } & \multicolumn{2}{|c|}{ Curitiba } & \multicolumn{2}{|c|}{ Uberlância } \\
\hline & $\begin{array}{c}\text { Avaliação } \\
\text { intermediária } \\
\text { (média/DP) }\end{array}$ & $\begin{array}{l}\text { Avaliação final } \\
\text { (média/DP) }\end{array}$ & $\begin{array}{c}\text { Avaliação } \\
\text { intermediária } \\
\text { (média/DP) }\end{array}$ & $\begin{array}{l}\text { Avaliação final } \\
\text { (média/DP) }\end{array}$ & $\begin{array}{c}\text { Avaliação } \\
\text { intermediária } \\
\text { (média/DP) }\end{array}$ & $\begin{array}{l}\text { Avaliação final } \\
\text { (média/DP) }\end{array}$ \\
\hline $\begin{array}{l}\text { Discussão de } \\
\text { casos }\end{array}$ & $4,2 \pm 0,76$ & $4,3 \pm 0,74$ & $4,5 \pm 0,54$ & $4,5 \pm 0,57$ & $4,4 \pm 0,61$ & $4,5 \pm 0,52$ \\
\hline $\begin{array}{l}\text { Projetos de } \\
\text { intervenção }\end{array}$ & $4,3 \pm 0,71$ & $4,3 \pm 0,73$ & $4,1 \pm 0,88$ & $4,5 \pm 0,65$ & $4,1 \pm 0,75$ & $4,3 \pm 0,70$ \\
\hline Ofertas teóricas & $4,1 \pm 0,80$ & $4,2 \pm 0,74$ & $4,5 \pm 0,55$ & $4,5 \pm 0,5$ & $4,4 \pm 0,670 / 8$ & $4,5 \pm 0,56$ \\
\hline
\end{tabular}

Dentre os três componentes, a oferta teórica (em Campinas) e projetos de intervenção (em Campinas e Uberlândia) receberam as menores médias. Por sua vez, o ponto forte da formação foi a discussão de casos/grupos Balint-Paideia. Sobre as ofertas teóricas, é possível que a quantidade e/ ou pertinência e acessibilidade dos textos utilizados tenham influenciado na avaliação. Ademais, o emprego de diferentes recursos pedagógicos, conforme a pactuação entre os professores/apoiadores e os alunos, dificulta a capacidade de sistematização e de autorreflexão crítica sobre o panorama geral.

"No início, ficamos resistentes em voltar a ler os textos lá do Paideia e também esperávamos ver ferramentas novas, textos novos (...) alguns de nós sentiram que as ofertas teóricas ficaram no básico do 'básico'e que não aprofundamos as discussões" (grupo focal de Campinas).

"Foi na oferta teórica onde mais divergimos metodologicamente e também onde encontramos as maiores dificuldades junto aos grupos. Alguns de nós, percebendo dificuldades, recorreram ao formato de aulas tradicionais 
(...) outros de nós acreditam ser fundamental romper com esse formato de aula tradicional e recorreram a outras estratégias como roteiro de perguntas e discussão de trechos específicos, além de outras dinâmicas de grupo para poder trabalhar o texto, tornando tudo mais participativo (...) No entanto, concordamos que tivemos pouco sucesso em articular a teoria com a prática ao discutir as ofertas teóricas e que os apoiadores queixavam-se da repetitividade dos textos e da ausência de bibliografia com recomendações mais diretas e objetivas sobre o Apoio Matricial" (grupo focal de professores).

Em contrapartida, quanto às discussões de casos, é provável que a proximidade de situações concretas conferida por esse recurso tenha impulsionado positivamente as avaliações e poderia ser incrementada para potencializar também as ofertas teóricas.

"Associada à discussão de caso, contávamos também com a implementação de projetos de intervenção. Neles, os apoiadores deveriam levar de volta para o território aquilo que se estava aprendendo no curso... era difícil, mas os alunos gostavam" (grupo focal de professores).

"Em vários de nossos projetos de intervenção, percebemos mudanças positivas no processo de trabalho. $O$ curso nos ajudou a olhar mais o contexto, a ter uma visão mais ampla do que era matriciamento e a reconhecer o valor das pequenas mudanças. Em muitos projetos, demos passos de formiga, mas alguns de nós alcançou até mudanças institucionais, a partir dessas pequenas ações” (grupo focal de Curitiba).

$\mathrm{Na}$ Tabela 4, é possível visualizar os temas das ofertas teóricas e dos projetos de intervenção (que derivaram das discussões de casos).

Sobre as contribuições positivas do curso, todas as turmas seguiram a mesma tendência, ou seja, atribuíram melhores notas para os mesmos itens, sendo eles: desenvolvimento pessoal (média 4,54 em Campinas; 4,69 em Curitiba e 4,63 em Uberlândia), o aumento da capacidade de empreender análise crítica (média 4,50 em Campinas; 4,94 em Curitiba e 4,47 em Uberlândia) e aquisição de conhecimentos teóricos (média 4,40 em Campinas; 4,81 em Curitiba e 4,65 em Uberlândia). Vale ressaltar que a avaliação positiva feita à aquisição de conhecimentos teóricos contrasta com as críticas feitas à oferta teórica.

"A gente se sente mais seguro, porque tem as diretrizes, o embasamento teórico e as ferramentas. Nas equipes, quando a gente falava "estou fazendo uma especialização em Apoio Matricial", parece que tínhamos um pouco mais de legitimidade" (grupo focal de Uberlândia).

A pior avaliação, em todas as turmas, com notas bastante inferiores às demais a respeito das contribuições do curso, foi acerca do item sobre democratização dos serviços (média 3,23 em Campinas; 3,69 em Curitiba e 3,65 em Uberlândia).

A democratização dos serviços é um dos principais objetivos pretendidos com a formulação do Apoio, dentro do Método Paideia 4. Entretanto, essa mudança foi fortemente modulada por aspectos políticos e pelo modelo de gestão, que, muitas vezes, era pouco participativo ou permeável às intervenções dos trabalhadores.

Outra ponderação refere-se à dificuldade de se mensurar os coeficientes de cogestão, associados a mudanças macropolíticas e a transformações institucionais 48. Logo, constituem um processo lento e gradual frente ao qual os produtos parciais de um curso inevitavelmente parecerão deveras modestos.

Sobre a prática profissional, os dispositivos/arranjos que apresentaram maiores médias, melhor avaliação, foram a discussão de casos (médias: 4,20 em Campinas; 4,44 em Curitiba e 4,35 em Uberlândia), a realização de Projeto Terapêutico Singular (médias: 4,04 em Campinas; 3,94 em Curitiba e 4,44 em Uberlândia) e a assistência direta (médias: 3,96 em Campinas; 4,63 em Curitiba e 4,31 em Uberlândia), indicando os aspectos em que mais se perceberam melhorias.

Esses dados reforçam a hipótese de que os alunos obtiveram maior sucesso em empreender mudanças no âmbito micropolítico 14. Algumas dessas discussões também apareceram nos grupos focais:

"Dentro das equipes, melhorou bastante, chegando a funcionar o Projeto Terapếutico singular e grupos (...) Às vezes, é difícil compatibilizar as agendas para as ações compartilhadas e acabamos trabalhando isolados, mas sabemos que não podemos desistir, porque a gente viu que realmente é muito produtivo" (grupo focal de Uberlândia).

“...reconhecemos que estamos mais sensiveis à relação de poder que ocorre entre todos nós, profissionais de saúde, e os usuários (...) começamos a enxergar onde devemos reconhecer e estimular o poder dos usuários (...) foi no nosso modo de exercer a clínica onde nós mais avançamos" (grupo focal de Curitiba). 
Tabela 4

Ofertas teóricas comuns aos três municípios e principais temas dos projetos de intervenção desenvolvidos durante a Formação Paideia.

\begin{tabular}{|c|c|c|}
\hline Tema & Bibliografia * & Abordagem ** \\
\hline Equipe de referência e Apoio & - Campos \& Domitti 9 & - Professor convidado \\
\hline Matricial & & - Discussão em roda \\
\hline \multirow[t]{2}{*}{ Apoio Paideia } & - Campos et al. 32 & - Leitura em subgrupos \\
\hline & & - Apresentação de síntese \\
\hline \multirow[t]{2}{*}{ Apoio institucional e Apoio Matricial } & - Oliveira \& Campos 15 & - Seminário dos alunos \\
\hline & & - Discussão em roda \\
\hline Clínica ampliada e compartilhada e & - Núcleo Técnico da Política Nacional de Humanização, & - Discussão em subgrupos para \\
\hline Projeto Terapêutico Singular & Secretaria de Atenção à Saúde, Ministério da Saúde 50 & $\begin{array}{l}\text { articular com a prática. Depois, } \\
\text { discussão em roda }\end{array}$ \\
\hline \multirow[t]{2}{*}{ Acolhimento } & - Núcleo Técnico da Política Nacional de Humanização, & - Seminários dos alunos \\
\hline & Secretaria de Atenção à Saúde, Ministério da Saúde 51 & - Discussão em roda \\
\hline \multirow[t]{3}{*}{ Atenção básica } & - Departamento de Atenção Básica, Secretaria de Atenção à & - Apresentação de slides \\
\hline & Saúde, Ministério da Saúde 1 & - Seminário de subgrupo com \\
\hline & - Campos et al. 52 & exemplos práticos \\
\hline \multirow[t]{2}{*}{ Modelos de atenção à saúde } & - Paim 53 & - Prof. Convidado \\
\hline & & $\begin{array}{l}\text { - Apresentação com a participação } \\
\text { dos alunos }\end{array}$ \\
\hline Trabalhador como sujeito: & - Onocko Campos 54 & - Seminário dos alunos com \\
\hline sofrimento no trabalho e trabalho & - Castilho Sá 55 & apresentação de exemplo prático \\
\hline em equipe & & $\begin{array}{c}\text { - Dinâmica de grupo proposta por } \\
\text { uma das alunas }\end{array}$ \\
\hline Educação permanente e função & - Campos 56 & - Alunos das diferentes turmas \\
\hline \multirow[t]{2}{*}{ pedagógica do apoiador } & $\begin{array}{l}\text { - Departamento de Gestão da Educação em Saúde, Secretaria } \\
\text { de Gestão do Trabalho e da Educação na Saúde, Ministério da }\end{array}$ & $\begin{array}{l}\text { trocaram narrativas, contando } \\
\text { experiências }\end{array}$ \\
\hline & Saúde- Brasil 22 & $\begin{array}{l}\text { - Discussão em roda articulando } \\
\text { teoria e as narrativas }\end{array}$ \\
\hline \multirow[t]{2}{*}{ Redes de atenção à saúde } & - Mendes 57 & $\begin{array}{c}\text { - Elaboração prévia de síntese pelos } \\
\text { alunos }\end{array}$ \\
\hline & & - Discussão em roda \\
\hline \multirow[t]{2}{*}{ NASF } & - Departamento de Atenção Básica, Secretaria de Atenção à & - Síntese em subgrupos \\
\hline & Saúde, Ministério da Saúde 58 & $\begin{array}{l}\text { - Discussão sobre a implantação do } \\
\text { NASF no respectivo município }\end{array}$ \\
\hline \multirow{3}{*}{$\begin{array}{l}\text { Intersetorialidade e promoção à } \\
\text { saúde }\end{array}$} & - Fernandez \& Mendes 59 & - Trabalho em subgrupos para \\
\hline & & $\begin{array}{c}\text { destacar trechos e articular com a } \\
\text { prática }\end{array}$ \\
\hline & & - Discussão em roda \\
\hline Campo e núcleo de saberes: & - Campos 60 & - Apresentação dos apoiadores/ \\
\hline trabalho em equipe & & $\begin{array}{l}\text { professores, com solicitação de tarefa } \\
\text { para a turma }\end{array}$ \\
\hline $\begin{array}{l}\text { Democracia institucional, gestão } \\
\text { compartilhada e espaços coletivos }\end{array}$ & - Campos 61 & $\begin{array}{l}\text { - Apresentação dos apoiadores/ } \\
\text { professores sobre os principais } \\
\text { conceitos }\end{array}$ \\
\hline
\end{tabular}

(continua) 
Apoio para construção de Projetos Terapêuticos Singulares

Articulação do cuidado em rede (atenção à saúde e intersetorial)

4

Apoio Matricial em serviços urgência/Emergência e hospitais

Cuidado à obesidade

Saúde da criança e do adolescente

Apoio para articular atenção às demandas escolares

Apoio para ações de Humanização

Apoio em Saúde Mental com articulação dos CAPS

Organização de grupos de cuidadores e grupos de educação em saúde

Implantação de equipes NASF e inserção das especialidades no NASF ou no Apoio Matricial para

atenção básica

Oferta de apoio à atenção básica a partir de laboratório de análises clínicas e de centrais de

esterilização de insumos

CAPS: Centros de Atenção Psicossocial; NASF: Núcleos de Apoio à Saúde da Família.

* Refere-se à bibliografia principal. Para todos os temas, havia proposição de bibliografia complementar, a ser indicada pelos alunos (individualmente ou em grupo).

** Abordagem metodológica principal utilizada na maioria das turmas. Observação: algumas adaptações, variações eram previsíveis em virtude da metodologia do curso.

\section{Contribuições e limites da Formação Paideia para o Apoio Matricial}

A avaliação aqui apresentada assumiu, como principais indicadores, as mudanças nos campos do saber, do poder e do afeto, assim como as contribuições para o aumento da capacidade de análise e de intervenção dos participantes 32 .

Um dos principais achados foi que a Formação Paideia se mostrou bastante suscetível a modulações político-administrativas conjunturais, dado que os cursos foram construídos em diferentes contextos das Secretarias Municipais, o que obrigou a equipe pedagógica a introduzir modificações nos cursos, tais como adaptações de temas para ofertas teóricas e limitações na extensão das intervenções pretendidas pelos alunos em seus projetos durante o curso, além de pequenos ajustes de periodicidade nas atividades presenciais. Outros estudos 14,26,31, também pontuaram que singularidades institucionais têm se mostrado elemento de grande influência na formação e na postura dos trabalhadores.

Em Campinas, a Formação Paideia foi entendida pelos alunos como uma possível retomada da diretriz de cogestão e de coconstrução do cuidado, sendo pior avaliada do que nos outros municípios, muito provavelmente, porque as discussões soavam como algo que já fora tentado, mas que ficou interrompido após o investimento no Método Paideia realizado em 2000/2001 pela gestão municipal. Somou-se a isso a frustração da expectativa de um possível "efeito mágico" de recuperação do que fora perdido.

Apesar disso, foi possível reconhecer contribuições positivas do curso para o cotidiano dos profissionais, para os processos de trabalho dos apoiadores; ensinamentos que facilitaram o trabalho na lógica da cogestão e do trabalho interdisciplinar, permitindo responsabilidade compartilhada pelos casos e a realização da clínica ampliada por meio da integração dialógica entre os serviços da rede.

Em Curitiba, havia um histórico de modelo de atenção fragmentado e de gestão autoritária, com recente investimento no Apoio e nos processos de cogestão, mediante a nova implantação do NASF (em poucos meses, foram implementadas 93 equipes de NASF) e a criação da função de apoiadores institucionais para aproximar a gestão central da gestão distrital. Entretanto, foram relatadas dificuldades para implementar esses projetos de governo.

O trabalho do Apoio Matricial estava organizado principalmente pela proposta do NASF, mas ainda pautado por isolamento das diferentes especialidades que compunham essas equipes de apoio. 
Foram priorizadas ações de regulação da fila para a atenção secundária, as discussões de casos mantinham-se burocratizadas e com baixo grau de corresponsabilização.

Dadas essas características, a formação buscou, em Curitiba, legitimar novas formas de trabalho, diversificando o leque de arranjos e dispositivos do apoio, além de propiciar que os apoiadores passassem a se sentir legitimados para os enfrentamentos necessários.

Em Uberlândia, o curso foi proposto por alguns grupos isolados da Secretaria Municipal de Saúde, pois a gestão daquela época não tinha como agenda o investimento no Apoio ou nos processos de cogestão. A Formação Paideia, em Uberlândia, precisou lidar com a fantasia de que o curso seria para apresentar um "modelo que dá certo" e também sofreu com a escassez de investimentos institucionais. Mesmo assim, conseguiu ajudar na implementação do NASF e apresentar elementos teóricos e práticos do apoio. No entanto, os profissionais precisaram lidar com a constatação de que o município não reverteria sua posição frente às novas propostas.

Portanto, em todos os municípios, a despeito das dificuldades conjunturais, foi possível perceber que a Formação Paideia obteve bons resultados no que se refere à ampliação da capacidade de análise dos estudantes e do seu desenvolvimento pessoal. Nesse sentido, avançou na produção do efeito Paideia, intervindo principalmente nas dimensões do saber e do afeto 32 .

Do mesmo modo, notou-se incremento na comunicação entre os serviços, fundamental para garantir o aumento da cobertura assistencial e a integralidade do cuidado.

No que diz respeito às fragilidades da Formação Paideia, foi possível reconhecer a baixa contribuição para ampliar a capacidade de intervenção dos profissionais em seu cotidiano de trabalho, o que revela quão difícil é alterar a dimensão "poder" institucional.

Ainda assim, é possível afirmar que os cursos provocaram desestabilizações em algumas relações de poder instituídas nas práticas das equipes. Como Foucault 49 , percebemos que o poder constitui um exercício ou um jogo de forças instável e permanente nas relações sociais, o que se expressa nas ações, não se constituindo como um atributo pessoal ou de uma coisa da qual podemos nos apoderar, tomar posse.

"Acreditamos que logramos fazer um bom curso e que ele ajudou a estimular a reflexão nos trabalhadores. Talvez, ele não tenha conseguido alcançar as transformações que almejávamos, mas saímos modificados de algum modo: nós, os trabalhadores e as instituições" (grupo focal de professores).

\section{Considerações finais}

O Método Paideia contribuiu na formação de profissionais em Apoio Matricial para que pudessem repensar e modificar sua prática, incorporando referenciais e dispositivos do trabalho interdisciplinar e da corresponsabilização pelo cuidado, valorizando espaços de discussão e de cogestão entre os profissionais e entre esses e os usuários e investindo em práticas de humanização, tais como o Projeto Terapêutico Singular.

Acredita-se que, com isso, o papel dos especialistas na atenção primária pôde ser problematizado no sentido de conferir maior contorno e resolubilidade às ações desses profissionais. E, por favorecer a aprendizagem a partir da prática, pôde constituir um incremento às propostas do ensino baseado em reflexão sobre a prática.

Quanto à sua metodologia, destacou-se a valorização dos espaços de discussão de casos, nos grupos Balint-Paideia, combinados com projetos de intervenção, que proporcionam reflexão ativa sobre a realidade do trabalho e sobre o referencial teórico.

Houve resultados positivos no que se refere ao aumento da capacidade de análise e a mudanças nas dimensões cognitiva e afetiva dos participantes, com modificação dos processos micropolíticos. Contudo, sua efetividade no incremento da capacidade de intervenção e na transformação das relações de poder precisaria ser potencializada por meio de sua inserção no escopo de mudanças nos modelos de atenção e de gestão dos municípios. 


\section{Colaboradores}

M. M. Oliveira Viana participou de todas as etapas do estudo; da concepção, do desenvolvimento e revisão do artigo. G. W. S. Campos participou de todas as etapas de produção e revisão do artigo.

\section{Agradecimentos}

A todos os profissionais do Apoio Matricial e aos participantes da pesquisa. À Capes pelo financiamento.

\section{Referências}

1. Departamento de Atenção Básica, Secretaria de Atenção à Saúde, Ministério da Saúde. Política Nacional de Atenção Básica. Brasília: Ministério da Saúde; 2012. (Série E. Legislação em Saúde).

2. Starfield B. Atenção primária: equilíbrio entre necessidades de saúde, serviços e tecnologia. Brasília: Organização das Nações Unidas para a Educação, a Ciência e a Cultura/Ministério da Saúde; 2002.

3. Starfield B. William Pickles Lecture. Primary and specialty care interfaces: the imperative of disease continuity. Br J Gen Pract 2003; 53:723-9.

4. Oliveira MM, Campos GWS. Apoios matricial e institucional: analisando suas construções. Ciênc Saúde Coletiva 2015; 20:229-38.

5. Ministério da Saúde. Portaria GM/MS no 154, de 24 de janeiro de 2008. Cria os Núcleos de Apoio à Saúde da Família - NASF. Diário Oficial da União 2008; 04 mar.

6. Ministério da Saúde. Portaria no 2.488, de 21 de outubro de 2011. Aprova a Política Nacional de Atenção Básica, estabelecendo a revisão de diretrizes e normas para a organização da Atenção Básica, para a Estratégia Saúde da Família (ESF) e o Programa de Agentes Comunitários de Saúde (PACS). Diário Oficial da União 2011;24 out.

7. Ministério da Saúde. Portaria no 3.124, de 28 de dezembro de 2012. Redefine os parâmetros de vinculação dos Núcleos de Apoio à Saúde da Família (NASF) Modalidades 1 e 2 às Equipes Saúde da Família e/ou Equipes de Atenção Básica para populações específicas, cria a Modalidade NASF 3, e dá outras providências. Diário Oficial da União 2012; 31 dez.

8. Campos GWS, Domitti AC. Apoio matricial e equipe de referência: uma metodologia para gestão do trabalho interdisciplinar em saúde. Cad Saúde Pública 2007; 23:399-407.

9. Cunha GT, Campos GWS. Apoio matricial e atenção primária em saúde. Saúde Soc 2011; 20:961-70.

10. Domitti ACP. Um possível diálogo com a teoria a partir das práticas de apoio especializado matricial na atenção básica de saúde [Tese de Doutorado]. Campinas: Faculdade de Ciências Médicas, Universidade Estadual de Campinas; 2006.

11. Tesser CD. Núcleos de Apoio à Saúde da Família, seus potenciais e entraves: uma interpretação a partir da atenção primária à saúde. Interface (Botucatu, Online) 2017; 21:565-78.

12. Tesser CD, Poli Neto P. Atenção especializada ambulatorial no Sistema Único de Saúde: para superar um vazio. Ciênc Saúde Coletiva 2017; 22:941-51 
13. Oliveira MM. Apoio matricial na atenção básica de campinas: formação e prática [Dissertação de Mestrado]. Campinas: Universidade Estadual de Campinas; 2014.

14. Feuerwerker LCM. Micropolítica e saúde: produção do cuidado, gestão e formação. Porto Alegre: Rede Unida; 2014.

15. Oliveira GN. Apoio Matricial como tecnologia de gestão e articulação em rede. In: Campos GWS, Guerrero AVP, organizadores. Manual de práticas de atenção básica: saúde ampliada e compartilhada. 2a Ed. São Paulo: Editora Hucitec; 2010. p. 273-82.

16. Melo EA. Caderno do curso Apoio Matricial na atenção básica com ênfase nos NASF: aperfeiçoamento. 2a Ed. Rio de Janeiro: Escola Nacional de Saúde Pública Sergio Arouca, Fundação Oswaldo Cruz; 2016.

17. Almeida Filho N. Reconhecer Flexner: inquérito sobre produção de mitos na educação médica no Brasil contemporâneo. Cad Saúde Pública 2010; 26:2234-49.

18. Nuto SAS, Noro LRA, Cavalsina PG, Costa ICC, Oliveira AGRC. O processo ensino -aprendizagem e suas consequências na relação professor-aluno-paciente. Ciênc Saúde Coletiva 2006; 11:89-96

19. Souza AN. Formação médica, racionalidade e experiência. Ciênc Saúde Coletiva 2001; 6:8796.

20. Carvalho YM, Ceccim RB. Formação e educação em saúde: aprendizados com a saúde coletiva. In: Campos GWS, Minayo MCS, Akerman M, Drumond Júnior M, Carvalho YM, organizadores. Tratado de saúde coletiva. 2 a Ed. São Paulo: Editora Hucitec; 2012. p. 137-70.

21. Oury J. Itinerários de formação. Revue Pratique 1991; 1:42-50.

22. Departamento de Gestão da Educação em Saúde, Secretaria de Gestão do Trabalho e da Educação na Saúde, Ministério da Saúde. Política nacional de educação permanente em saúde. Brasília: Ministério da Saúde; 2009. (Série B. Textos Básicos de Saúde). (Série Pactos pela Saúde 2006, 9)

23. Raelin JA. A model of work-based learning. Organization Science 1997; 8:563-78.

24. Billett S. Workplace learning: its potential and limitations. Education and Training 1994; 37:20-7.

25. Vernon DTA, Blake RL. Does problem-based learning work? A meta-analysis of evaluative research. Acad Med 1993; 6:550-63.

26. Gonçalves DA, Fortes S, Campos M, Ballester D, Portugal FB, Tófoli LF, et al. Evaluation of a mental health training intervention for multidisciplinary teams in primary care in Brazil: a pre- and posttest study. Gen Hosp Psychiatry 2013; 35:304-8
27. Castro CP. Avaliação da utilização do método de apoio Paideia para a formação em saúde: clínica ampliada e cogestão [Dissertação de Mestrado]. Campinas: Universidade Estadual de Campinas; 2011.

28. Castro CP, Campos GWS. Apoio Institucional Paideia como estratégia para educação permanente em saúde. Trab Educ Saúde 2014; 12:29-50.

29. Cunha GT. Grupos Balint-Paideia: uma contribuição para a cogestão e a clínica ampliada na Atenção Básica [Tese de Doutorado]. Campinas: Universidade Estadual de Campinas; 2009.

30. Cunha GT, Dantas DV. Uma contribuição para a cogestão da clínica: grupos Balint-Paideia. In: Campos GWS, Guerrero AVP, organizadores. Manual de práticas de atenção básica: saúde ampliada e compartilhada. São Paulo: Editora Hucitec; 2010. p. 34-60.

31. Figueiredo MD. A construção de práticas ampliadas e compartilhadas em saúde: apoio Paideia e formação [Tese de Doutorado]. Campinas: Universidade Estadual de Campinas; 2012.

32. Campos GWS, Cunha GT, Figueiredo MD. Práxis e formação Paideia: apoio e cogestão em saúde. São Paulo: Editora Hucitec; 2013.

33. Brasil. Lei no 8.080 , de 19 de setembro de 1990. Dispõe sobre as condições para a promoção, proteção e recuperação da saúde, a organização e o funcionamento dos serviços correspondentes e dá outras providências. Diário Oficial da União 1990; 20 set.

34. Tripp D. Pesquisa-ação: uma introdução metodológica. Educação e Pesquisa 2005; 31:44366.

35. Pezzato LM, Prado GVT. Pesquisa-ação e pesquisa-intervenção: aproximações, distanciamentos, conjugações. In: L'Abbate S, Mourão LC, Pezzato LM, organizadores. Análise institucional \& saúde coletiva. São Paulo: Editora Hucitec; 2013. p. 149-70.

36. L'Abbate S. Análise institucional e intervenção: breve referência à gênese social e histórica de uma articulação e sua aplicação na saúde coletiva. Mnemosine 2012; 8:194-219.

37. L’Abbate S, Mourão LC, Pezzato LM. Análise institucional \& saúde coletiva. São Paulo: Editora Hucitec; 2013. 
38. Minayo MCS. O desafio do conhecimento: pesquisa qualitativa em saúde. 12a Ed. São Paulo: Editora Hucitec; 2010.

39. Molina R, Garrido E. A produção acadêmica sobre pesquisa-ação em educação no Brasil: mapeamento das dissertações e teses defendidas no período 1966-2002. Formação Docente 2010; 2:27-40.

40. Aguiar KF, Rocha ML. Micropolítica e o exercício da pesquisa-intervenção: referenciais e dispositivos em análise. Psicol Ciênc Prof 2007; 27:648-663.

41. Trad LAB. Grupos focais: conceitos, procedimentos e reflexões baseadas em experiências com o uso da técnica em pesquisas de saúde. Physis (Rio J.) 2009; 19:777-96.

42. Westphal MF, Bógus CM, Faria MM. Grupos focais: experiências precursoras em programas educativos em saúde no Brasil. Bol Oficina Sanit Panam 1996; 120:472-82.

43. Furtado JP, Campos RO. Participação, produção de conhecimento e pesquisa-avaliativa: a inserção de diferentes atores em uma investigação em saúde mental. Cad Saúde Pública 2008; 24:2671-80.

44. Lourau R. René Lourau na Uerj. Análise institucional e práticas de pesquisa. Mnemosine 2007; 3:7-48.

45. Oliveira MK. Vygotsky: aprendizado e desenvolvimento: um processo sócio-histórico. São Paulo: Editora Scipione; 1997.

46. Freire P. Pedagogia da autonomia: saberes necessários à prática educativa. 49a Ed. Rio de Janeiro: Paz e Terra; 2014.

47. Pichon-Rivière E. O processo grupal. 8a Ed. São Paulo: Editora WMF Martins Fontes; 2012. (Coleção Textos de Psicologia).

48. Rocha ML. Pesquisa Intervenção e a produção de novas análises. Psicol Ciênc Prof 2003; 23:64-73.

49. Foucault M. Genealogia e poder. In: Foucault M, organizador. Microfísica do poder. 23a Ed. Rio de Janeiro: Edições Graal; 2007. p. 167-77.

50. Núcleo Técnico da Política Nacional de Humanização, Secretaria de Atenção à Saúde, Ministério da Saúde. Política Nacional de Humanização. Clínica ampliada, equipe de referência e projeto terapêutico singular. Brasília: Ministério da Saúde; 2008. (Série B. Textos Básicos de Saúde).

51. Núcleo Técnico da Política Nacional de $\mathrm{Hu}-$ manização, Secretaria de Atenção à Saúde, Ministério da Saúde. Acolhimento nas práticas de produção de saúde. Brasília: Ministério da Saúde; 2010. (Série B. Textos Básicos de Saúde).
52. Campos GWS, Gutiérrez AC, Guerrero AVP, Cunha GT. Reflexões sobre a atenção básica e a estratégia de saúde da família. In: Campos GWS, Guerrero AVP, organizadores. Manual de práticas de atenção básica: saúde ampliada e compartilhada. São Paulo: Editora Hucitec; 2010. p. 132-53.

53. Paim JS. Modelos de atenção à saúde no Brasil. In: Giovanella L, Escorel S, Lobato LVC, Noronha JC, Carvalho AI, organizadores. Políticas e sistema de saúde no Brasil. Rio de Janeiro: Editora Fiocruz; 2008. p. 547-73.

54. Onocko Campos R. Psicanálise e saúde coletiva: interfaces. São Paulo: Editora Hucitec; 2014.

55. Castilho Sá M. Subjetividade e projetos coletivos: mal-estar e governabilidade nas organizações de saúde. Ciênc Saúde Coletiva 2001; 6:151-64.

56. Campos GWS, Cunha GT, Figueiredo MD. A formação em saúde e o Apoio Paideia: referenciais teórico-metodológicos. In: Campos GWS, Cunha GT, Figueiredo MD, organizadores. Práxis e formação Paideia: apoio e cogestão em saúde. São Paulo: Editora Hucitec; 2013. p. 123-96.

57. Mendes EV. As redes de atenção à saúde. Ciênc Saúde Coletiva 2010; 15:2297-305.

58. Departamento de Atenção Básica, Secretaria de Atenção à Saúde, Ministério da Saúde. Núcleo de apoio à saúde da família - volume 1: ferramentas para a gestão e para o trabalho cotidiano. Brasília: Ministério da Saúde; 2014. (Cadernos de Atenção Básica, 39).

59. Westphal MF. Promoção da saúde e qualidade de vida. In: Fernandez JCA, Mendes R, organizadores. Promoção da saúde e gestão local. São Paulo: Editora Hucitec; 2007. p. 6-24.

60. Campos GWS. Saúde pública e saúde coletiva: campo e núcleo de saberes e práticas. Ciênc Saúde Coletiva 2000; 5:219-30.

61. Campos GWS. Democracia institucional e cogestão de coletivos organizados para a produção. In: Campos GWS, organizador. Um método para análise e cogestão de coletivos. São Paulo: Editora Hucitec; 2015. p. 121-84. 


\section{Abstract}

The study analyzed the use of the Paideia Method for training professionals that use matrix support in Curitiba (Paraná State), Uberlândia (Minas Gerais State), and Campinas (São Paulo State), Brazil. An 18-month training process (Specialization Course) was developed for this purpose with matrix support professionals. This was a qualitative study inspired by action-based research, research-intervention, and evaluation by triangulation of methods. Data production used field observation strategies with records kept in a field diary, semi-structured interviews with a questionnaire, and focus group. Data from the questionnaires were submitted to descriptive analysis. The qualitative data collected with participant observation and focus groups were analyzed with the construction of narratives. The study showed that Paideia Training fostered changes in the work process and in clinical practice among the teams. However, the full utilization of the matrix support methodology is heavily influenced by the institutional setting and management and healthcare models. An important difference was observed between the fields according to the degree of democratization and management's support for organizational changes.

Public Health Practice; Staff Development; Health Human Resource Training; Health Management

\section{Resumen}

La investigación analizó la utilización del Método Paideia en la formación de profesionales que utilizan apoyo matricial en Curitiba (Paraná), Uberlândia (Minas Gerais) y Campinas (São Paulo). Con este fin, se desarrolló un proceso de formativo (curso de especialización), según la estrategia Paideia, con 18 meses de duración, para profesionales de apoyo matricial. Se trata de una investigación cualitativa, que se inspira en la investigaciónacción, en la investigación-intervención y en la evaluación por triangulación de métodos. En la producción de datos, se utilizaron estrategias de observación de campo, con registro en un diario de campo, entrevistas semiestructuradas -mediante cuestionarios- $y$ un grupo focal. Para los datos obtenidos con los cuestionarios, se realizó un análisis descriptivo. Respecto a los datos cualitativos, obtenidos mediante la observación participante y de los grupos focales se analizaron mediante una construcción de narraciones. El estudio señaló que la Formación Paideia favoreció cambios en el proceso de trabajo y en la práctica clínica de los equipos investigados. Se observó, no obstante, que la plena utilización de la metodología de apoyo matricial está fuertemente influenciada por el contexto institucional, por los modelos de gestión y de atención, constatándose una diferencia importante entre los campos, según el grado de democratización y apoyo a la gestión de cambios organizativos.

Práticas de Salud Pública; Desarrollo de Personal; Capacitación de Recursos Humanos en Salud; Gestión en Salud
Recebido em 19/Jul/2017

Versão final aprovada em 14/Jan/2018

Aprovado em 15/Fev/2018 